\title{
Las dimensiones éticas de lo público
}

Fabián Corral Burbano de Lara

Por largo tiempo, algunas doctrinas, los lugares comunes predominantes y el proceso de simplificación del pensamiento, mantuvieron arrinconada a la ética en los obscuros rincones de la intimidad personal. Se esforzaron los pensadores en marcar distancias entre el derecho positivo y la moral y en convertir a la ley en puro objeto de la técnica jurídica, icono neutro labrado por la lógica. Así, las constituciones, transformadas en creaciones ideológicas desconectadas de la realidad, se impusieron a los pueblos como vestuarios cortados por la sabia tijera del racionalismo.

La pretensión de moldear a las sociedades desde la caprichosa perspectiva de las doctrinas desembocó en las peores tiranías. El positivismo extremo y su hijo, el despotismo de los legisladores, fueron buenos aliados del totalitarismo.

América Latina es dramático ejemplo de la inadecuación de los sistemas normativos a la realidad y de la consiguiente ineficacia de la ley entendida como presupuesto ideológico abstracto, a tal punto que, sin apartarnos del rigor analítico, y más allá de las metáforas que inspiran los episodios públicos de nuestros países, se puede afirmar que lo que tenemos no son estados de derecho -según la clásica propuesta de los pensadores liberales- sino anómalos estados sin derecho donde prosperan los monopolios públicos y privados, un mercantilismo rampante y la frustración colectiva derivada, en parte, de la inseguridad jurídica, de la falta de proyectos nacionales que entusiasmen a la colectividad y de la frondosa expedición de reglas secundarias que, en la práctica, derogan las garantías constitucionales y neutralizan los derechos ciudadanos.

Pocos repararon, durante el auge del constitucionalismo formal que por ciento setenta años ha sembrado incertidumbre en Latinoamérica, que la democracia no es problema de reglas únicamente; que el estado de derecho no se edifica sobre el frágil terreno de los presupuestos teóricos; que la economía de mercado es tema que tiene que ver con la idiosincrasia y la cultura, y que debe estar empapada por la ética; que los gobiernos, su inestabilidad o su durabilidad, están vinculados con las lealtades que la gente común les presta y con la credibilidad que suscitan en cada ciudadano; que la ley rige eficazmente cuando se convierte en costumbre social, y que la vigencia jurídica de las normas debe estar avalada por la vigencia social de los supuestos en que la juridicidad se apoya.

Pocos admitieron que el ordenamiento legal debe plantarse en la cultura; que el sistema legal debe considerar, articular y defender los valores predominantes y respetar las nociones morales de la comunidad. La ilusión de la modernidad obscureció la capacidad de análisis y la humilde realidad dejó de tomarse en cuenta. Prevalecieron, entonces, las consideraciones hipotéticas, las brillantes abstracciones y la retórica discursiva. La ley se convirtió en ícono soberbio y la realidad fue vista como la especie hirsuta y montaraz que debía amoldarse a los cánones impuestos por los ilustrados. 
Probablemente en la falta de sintonía entre la abstracción constitucionalista, el positivismo abstracto y la realidad cultural y social, esté la clave para entender lo que ocurre en América Latina y en Ecuador, cuyo drama radica en la eterna búsqueda de identidad política, en la permanente confusión pública y en los perversos sucedáneos generados para reemplazar, siempre provisoriamente, a instituciones que no cuajan y a los deber ser que no prosperan. Por eso, parece apropiado aproximarse en esta oportunidad a las dimensiones éticas de lo público y a las lealtades que deberían afianzar la democracia, es decir a los soportes extrajurídicos de la legalidad y a los referentes extrapolíticos de la política.

Si las instituciones de la democracia y el capitalismo quieren funcionar adecuadamente, deben coexistir con ciertos hábitos culturales premodernos que aseguren su correcto funcionamiento- dice Francisco Fukuyama- Y agrega: Las leyes, los contratos y la racionalidad económica, proporcionan unas bases necesarias pero no suficientes para mantener la estabilidad y prosperidad de las sociedades postindustriales; pero también es preciso que cuenten con reciprocidad, obligaciones morales, responsabilidad hacia la comunidad y confianza, la cual se basa más en un hábito que en un cálculo racional. Esto último no significa un anacronismo para la sociedad moderna, sino más bien el sine qua non de su éxito. ${ }^{1}$

Lo que intento aquí, por cierto, es una somera y provisional aproximación a tan arduos temas bajo el presupuesto de que el Derecho, como ley (Law), y los derechos como potestades y poderes individuales (rights), tienen que ver con la ética y con la cultura y que lo público no se agota en la Constitución, ni en las instituciones, ni en la burocracia, ni en los noticieros ni en los titulares de primera página.

\section{El imposible gobierno desde arriba ${ }^{2}$}

Es una quimera suponer que sin la virtud del pueblo, alguna forma de gobierno pueda asegurar la libertad o la felicidad, escribió James Madison. Así, con certeza y claridad, aludió al tema de la insuficiencia de los poderes entendidos exclusivamente como potestades legales desconectadas de sus bases de legitimación social y de participación ciudadana. Podemos decir, en la línea de pensamiento de Madison, que el buen gobierno exige buen pueblo.

Efectivamente, temas como la gobernabilidad, la eficiencia de las instituciones, la devaluación del servicio público, la credibilidad de la autoridad y la funcionalidad de la democracia tienen que ver con la necesidad, cada vez más admitida y creciente, de que el mundo jurídico que norma a la función pública busque su sustento no solo en la validez formal de las reglas, en su perfección técnica o en su razonabilidad ideológica, ni tan solo en su potencial representatividad política, sino, además, en una red extra legal de lealtades $y$ valores que viniendo de la ciudadanía, la vinculen con el poder; que comprometan a la sociedad civil más allá del mandato jurídico y que coloquen a la autoridad en el incómodo pero necesario esquema de rendición de cuentas moral, que afiance y dote de soporte social a los métodos de control jurídico y a las responsabilidades legales.

1. Fukuyama, Francisco. Trust. 1995. pág.11

2. Adela Cortina habla del imposible estado de derecho, en Hasta un pueblo de demonios. 1998. 
El gobierno desde arriba -entendido como el poder político formal, como autoridad y mando- y el Estado de derecho, son imposibles en la práctica -ineficaces en la terminología de Norberto Bobbio- si a las reglas jurídicas y a los controles políticos no se suman eficientes, oportunos y legítimos sistemas de control social implícito que operan desde el estado llano y en un ámbito distinto al de la ley. Eso supone, empero, que el pueblo tenga valores, que la conducta de la mayoría respecto de los asuntos de interés público funcione referida no solamente a intereses sino también a lealtades. Implica, por otra parte, que a la gente le importe el poder, y que correlativamente al poder le interese la credibilidad de los gobernados, no para manipularla con recursos demagógicos derivados de empleo cínico de los sondeos, sino para adecuar su conducta y sus estilos a las exigencias morales de la sociedad civil.

La coincidencia entre el interés y el entusiasmo de los ciudadanos por el buen gobierno -por su transparencia, honradez y eficiencia- y la correlativa importancia que los gobernantes den a la credibilidad pública como concepto ético, constituyen el nexo que hace posible el gobierno desde arriba. Y esto porque la gobernabilidad y la funcionalidad del sistema político tienen vinculación esencial con la confianza que es producto ciudadano que crece cuando la autoridad crea las condiciones para ello. La integridad en el manejo de la cosa pública potencia, suscita y despierta el apetito de integridad de la sociedad civil. Al contrario, la corrupción y el cinismo de gobernantes y partidos genera desaliento, tolerancia y admisión del ambiente de impunidad que es el más indicado para que prospere y se afiance la corrupción.

El poder necesita encontrarse- coincidir en algún punto- con la sociedad civil en el terreno de la ética. Si ese encuentro no se da, se devalúa la legitimidad de la autoridad y del sistema político, es decir, se evapora la justificación moral del derecho a mandar. En los problemas de ingobernabilidad está latente la deslegitimación de la función pública; probablemente por eso en los últimos tiempos aparece con tanta fuerza la necesidad de encontrar y revaluar los soportes éticos de la autoridad, que pasaron de moda en los tiempos de auge de la modernidad positivista.

Estos razonamientos son más evidentes, y más acuciante la necesidad de ponerlos en práctica, cuando se examina el tema en la perspectiva de los gobiernos locales, porque ellos no son sino el vecindario organizado o la visión cercana de la política y del servicio público. Mientras más próximo esté el poder y la administración a la sociedad civil, más importante es el concepto de integridad y la cultura de transparencia que deben actuar no como sucedáneos de los controles jurídicos, sino como su soporte social. Los valores o los antivalores- son el aire que respiran las instituciones. La cultura es el ambiente en el que se mueve la ley.

La necesidad de una ética pública y de conductas leales de los gobernantes frente a las expectativas y aspiraciones de los ciudadanos, y, a la vez, la necesidad de que la sociedad civil milite activamente por la integridad, tienen que ver con la legitimidad del sistema democrático, porque ... es difícil justificar la obligación de obedecer al derecho si tiene un nivel notable de corrupción. ${ }^{3}$

3. Calsamiglia, Alberto. Cuestiones de lealtad. Madrid. 2000, pág. 23. 
Más aún, ... el intento de "juridificar" las relaciones de poder y que éstas no tengan otro sustrato que el estrictamente jurídico puede ser una de las causas de la emergencia de la corrupción. Allí donde existen lazos jurídico-políticos reforzados por otro tipo de lazos de carácter social, la corrupción se dificulta. ${ }^{4}$

Victoria Camps, en la misma línea de pensamiento; escribió que Si los principios son insuficientes, también lo son las normas y las leyes. Lo son porque no todo se resuelve legislando ni las leyes son la mejor manera de hacer que funcione adecuadamente una comunidad de ciudadanos maduros y autónomos. Lo que cohesiona a la comunidad son las costumbres y la responsabilidad de los individuos frente a ellas. Montesquieu dijo que "cuando un pueblo tiene buenas costumbres, las leyes son sencillas. ${ }^{5}$

En otro texto, la misma Victoria Camps dice que... el deber de un gobierno democrático es ser transparente, hacer público lo que hace. También el deber ciudadano - y en especial el de los representantes del ciudadano: el parlamento- es exigirle al gobierno que explique por qué hace lo que hace o deja de hacer. Como hemos podido observar en la experiencia política reciente, la deslegitimación de los gobiernos no tiene su causa sólo en transgresiones de la ley denunciadas y sentenciadas por los jueces. Es la incoherencia ideológica, el incumplimiento de lo prometido, la inacción política, la omisión de respuestas lo que desilusiona a los electores y hace que cunda el descrédito. ${ }^{6}$

La necesidad de lo que llamaremos el vínculo ético entre el gobierno y la sociedad civil, tiene que ver con el hecho incuestionable de que los controles políticos, las reglas jurídicas y aún el escándalo no han sido medios de corrección suficientes frente a la corrupción, porque a todos aquellos métodos no les acompaña una red de lealtades, principios y valores que le importen a la gente y que actúen como apoyo y soporte de los controles legales. El inventario racional de esas lealtades, de esas responsabilidades y consideraciones cívicas, de esos referentes es lo que, con alguna impropiedad, se ha llamado el código de ética y lo que podría denominarse también las reglas de integridad.

Hay que advertir que esas reglas de integridad no pueden consistir en un código más o menos juridificado de reglas de comportamiento. Convertir a la ética en norma jurídica es grave error. De lo que se trata es de identificar, y quizá reconstituir, valores sobre los cuales una sociedad determinada ancle su vida, referentes que formen parte de sistemas de control social, conductas apreciadas por la comunidad, estilos de vivir y gobernar que coincidan con los perfiles de humanidad, compromisos y responsabilidades que la sociedad civil ha venido labrando en su cultura. Se trata de descubrir y hacer patentes los limites, iniciativas, formas de ser y hacer que coinciden con la jerarquía valorativa de una sociedad, y lograr por esa vía el rescate de la ética en los negocios y en el gobierno; se trata de comprometer conductas, generar o hacer patentes lealtades que la comunidad aprecia porque vive sobre ellas, porque encarnan sus ideales y porque, además, crean un ambiente de confianza que motiva e induce a comportamientos razonables.

Se trata de que la gente, mirando la acción de su gobierno -la transparencia de sus procedimientos y su eficiencia llegue a creer en él, y que esa credibilidad evapore las dudas que el ciudadano usualmente tiene acerca de la utilidad de pagar impuestos,

\footnotetext{
4. Op. cit, pág. 23.

5. Camps, Victoria y Salvador Giner. Manual de Civismo. Ariel, 1999. pág. 139.

6. Camps, Victoria. El malestar de la vida pública. Grijalbo, 1996, pág.50.
} 
porque se roban los fondos públicos o politiquean con ellos o de obedecer a la autoridad y a la ley. Se trata de potenciar la confianza, de revaluar la función pública y de meter en la política lealtades mutuas que obliguen a la comunidad y a la autoridad con más fuerza que la norma legal.

\section{Democracia legítima y democracia eficiente}

La autoridad -toda autoridad y todo poder- entraña un problema esencial: la necesidad de superar la sensación de servidumbre, de renuncia a la libertad, de sumisión de los que obedecen. Ese problema, en buena medida, se remedia cuando existe en el ciudadano la intuición de que se debe cumplir lo que manda la ley y lo que dispone el poder, no solo en mérito a la capacidad coercitiva de la norma, sino además porque existen fuertes razones éticas para hacerlo, y siempre que la autoridad nos de a cambio un poco de seguridad, de equidad y de orden. El pacto social entraña obligaciones y contrapartidas mutuas para que se mantenga intangible.

El poder no sirve, esto es, carece de propósito y de objeto, más aún es ilegítimo, cuando no entrega a la comunidad y a las personas una situación que haga posible que cada ciudadano, con su esfuerzo, alcance la felicidad individual. Esa situación se llama el bien común y es lo que justifica la existencia del Estado, del Municipio y de las demás instituciones de la República. José Antonio Marina, en un brillante ensayo, descubre y destaca la vinculación que existe entre la felicidad personal y lo que él llama la felicidad política. Dice Marina: La felicidad política es una condición imprescindible para la felicidad personal. Hemos de realizar nuestros proyectos más íntimos, como el de ser feliz, integrándolos en proyectos compartidos como el de la justicia. Más adelante dice el autor tenemos, pues, que hablar de dos tipos de felicidad. Una es la felicidad subjetiva, un sentimiento pleno de bienestar personal, íntimo. Otra es la felicidad objetiva, pública, política, social, que no es un sentimiento sino una situación, el marco deseable para vivir, aquel escenario donde la "búsqueda de la felicidad"... resulta más fácil y tiene más garantías de éxito.

Hans Kelsen escribió que ... la búsqueda de la justicia es la eterna búsqueda de la felicidad humana. Es una finalidad que el hombre no puede encontrar por si mismo, y por ello la busca en la sociedad. La justicia es la felicidad social, garantizada por un orden social. ${ }^{8}$

La corrupción quita razones morales a la obediencia. Un poder corrupto e ineficiente se convierte en rival de la gente, en conspirador contra sus valores y en zapador de su felicidad. Esto es claro en los servicios públicos nulos o malos, en las obras deficientes y tardías, en los sistemas educativos precarios y politizados, en las contrataciones irregulares, etc. Entonces, surge la pregunta ¿tiene la obediencia límites cuando el poder se deslegitima, cuando la República, los municipios y gobiernos locales, dejan de ser cosa pública o cosa nuestra en la terminología de Adela Cortina, para transformarse en cosa de los otros, en coto privado donde cazan oportunidades los allegados y los bendecidos por los dueños del destino colectivo?

La democracia como forma de nominar a la autoridad, como sistema de responsabilidades públicas y de rendición de cuentas es, sin duda, el menos malo de los

7. Marina José Antonio. La lucha por la dignidad. Edit. Anagrama, Barcelona 2000 pág. 30-31.

8. Kelsen, Hans, Qué es la Justicia? Ariel Barcelona 1991, pág. 59. 
sistemas de gobierno inventados por el hombre. El Estado de Derecho es un método eficiente para superar los rezagos de servidumbre que implica toda obediencia y para poner límite a la arbitrariedad que potencialmente existe en todo poder. La democracia y el Estado de Derecho se encaman en la Constitución y en la ley. Pero algo más que la ley necesita la comunidad para prosperar y vivir. Algo más que la ley requiere el Estado para ejercer la autoridad y articular un proyecto duradero. Bastante más que la ley espera y exige el ciudadano para obedecer y entregar contribuciones importantes al erario público. Y ese algo es la legitimidad del sistema, la justificación moral de la autoridad, el sustento ético de las reglas y su coincidencia con la jerarquía de valores de la sociedad. Ese algo es la confianza.

Además de legítima, la democracia, como forma de gobierno debe ser eficiente y confiable. Debe medírsela por su representatividad, pero también por sus resultados humanos, sociales y económicos. Por tanto, ¿es tolerable, respetable y legítima la democracia ineficiente?

Los gobiernos locales están implicados y comprometidos en forma mucho más compleja con el tema de la legitimidad de la democracia eficiente. Ellos son los proveedores de oportunidades y servicios a la comunidad. Ellos son los gestores, planificadores y constructores de múltiples obras públicas. Con frecuencia, están a cargo de asuntos esenciales como la educación, la salud y la seguridad. Ellos contratan y ejecutan. Ellos son, por tanto, el primer escenario y el más cercano en que se prueba la eficiencia o ineficiencia de la democracia.

Algunos gobiernos a causa de su ineficiencia, corrupción o falta de planificación en su trabajo, abren en la comunidad la enorme y complicada interrogante de si la democracia es buena y legítima solamente porque es democracia, o si, además, debería exigírsele justificaciones por sus resultados y por el grado de oportunidades que los ciudadanos tienen cuando viven en un régimen de derecho y de representación política, que asegura, cierto es, el voto, la vigencia de la Constitución y hasta la libertad formal, pero que, con frecuencia, a la mayoría de la gente no le brinda oportunidades para vivir y crecer con razonable dignidad.

La legitimidad moral de un régimen toca, en muchos aspectos, con la eficiencia en la prestación de los servicios y en la ejecución de las obras, y con la transparencia en las conductas públicas. De allí que tenga tanta importancia la rendición de cuentas de que nos ocuparemos más adelante.

La democracia que legitima formalmente a muchos gobiernos, además de ser un sistema idóneo para elegir a los cuadros gobernantes, debe ser -como en algunos sitios en que ya ha logrado tan importantes cotas- un medio apropia do para alcanzar cierto grado de progreso. La democracia ineficiente no es democracia verdadera. La ineficiencia pública y la corrupción provocan pobreza y la pobreza disminuye o anula la libertad real. El analfabetismo, la desnutrición, la falta de vías suprimen, o al menos dificultan gravemente la capacidad de elegir con responsabilidad y permiten que la gente sea presa de la demagogia y el populismo. O que esa gente quede sumida en la indolencia, en la permisión y en el consentimiento de prácticas de corrupción. 
Desde la perspectiva de la sociedad civil, lo más grave quizá es que los gobiernos con visos de corrupción e ineficiencia, erosionan la confianza, matan los referentes de la comunidad, devalúan el prestigio de las instituciones, inauguran la negociación de las reglas. De ese modo la sociedad se inmoraliza y tiende al cinismo y a la admisión de prácticas corruptas como formas normales de manejar la función pública y la empresa.

El más serio mandato moral que encierra la democracia es su implícito compromiso ético de fomentar la confianza de los ciudadanos y de generar una sensación de bienestar y seguridad personal de vivir en un régimen representativo. La democracia ineficiente mata la fe en la democracia buena. Por eso, tema central de las reglas de integridad de los gobiernos es el de conciliar la representatividad política, el poder responsable y limitado, con la oportunidad y eficiencia del servicio público y con la idoneidad de la obra pública y la transparencia de la gestión Si queremos que la democracia deje de ser exclusivamente una versión constitucional y formal del poder y se transforme en un valor social, que comprometa y apasione a los ciudadanos, hay que pasar de la democracia declarativa de derechos a la democracia eficiente en términos sociales, económicos, culturales y humanos.

Aquí hay una tarea grande que, sin duda, toca a la integridad, a la ética pública y a la moral política, vistas todas ellas desde la lógica de una ciudadanía protagonista de su vida y militante por sus libertades y derechos.

\section{El sentido económico de la ética}

Los gobiernos, los empresarios y, en general, los administradores públicos y privados deberían ver a la ética desde el punto de vista de la conveniencia económica. Esto implica, por supuesto, un serio esfuerzo ideológico, educativo, moral y políti$\mathrm{co}$, porque en buena parte de las sociedades que han perdido los referentes éticos, se ha extendido la errónea idea de que la honradez es mal negocio. Más aún, con alta dosis de cinismo, se sostiene que no es posible la obra o el servicio público sin la interferencia de la corrupción como mal necesario o, al menos, como evento tolerable.

La derrota ética que semejantes apreciaciones implican, encuentra su peor vertiente en la legitimación de la coima como práctica en la administración, y en la resignación de mandatarios y ciudadanos que empiezan a contabilizar las prebendas, los pagos irregulares y otros métodos de corrupción como costos que deben considerarse en la liquidación normal de la obra y en la determinación de las tarifas.

Para los países, los gobiernos y las empresas privadas o públicas la corrupción es un costo tan elevado que desnaturaliza la función de la economía sana, pervierte la competencia y encarece la aplicación del derecho. Por eso, tratándose de un tema relacionado con la integridad de la acción de los gobiernos, conviene mirar a la ética desde la perspectiva de su función económica. Conviene ya no solo hablar y pensar en el mercado como instancia puramente económica, sino en el mercado como espacio de transacción donde actúan personas, empresas y administradores públicos que, finalmente, son o están representados por personas con cargas éticas y obligaciones frente a la comunidad. Hay que hablar, como alguien decía, del mercado de la virtud. ${ }^{9}$

9. Baurmann, Michael. 1998 
Las conductas ajustadas a los valores y limitadas por las convicciones ahorran costos, transparentan las transacciones y aseguran la calidad de las obras y servicios. Ante la extensión de la corrupción, los sistemas legales responden agregando controles, funcionarios y oficinas que sirven de poco frente a la voracidad de las mafias que circundan a la administración. Esos controles son costos para los gobiernos y para las empresas. Por otra parte, son malos negocios para el Estado y los ciudadanos las obras públicas defectuosas, los contratos obtenidos al influjo de prácticas ilegales, los funcionarios que encarecen las actividades legítimas facilitando las ilegítimas. Las obras innecesarias, las compras inconvenientes y la aplicación torpe e interesada de la ley le cuestan a la comunidad miles de millones de dólares. La corrupción es el hueco negro de la economía libre.

Aun desde el enfoque puramente económico de los comportamientos sociales, aun abstrayendo a las conductas administrativas de consideraciones éticas, resulta evidente que, desde la perspectiva puramente utilitaria, en términos de resultados y de satisfacción de necesidades, es mejor el servicio público eficiente y la obra pública ejecutada con transparencia, que servicios y obras viciados por la corrupción.

Adela Cortina dice que ... los actos de corrupción perjudican directamente a la persona 0 personas estafadas, sea el ciudadano en el caso de la corrupción política, sea el cliente en el caso de la empresarial... sin embargo, el daño causado no se limita a la estafa puntual que, aunque en ocasiones muy puntuales podría ser en parte reparado, sino que se amplía al hecho irreversible de que actuaciones como estas erosionan la credibilidad de las instituciones y minan la confianza en ellas. Y agrega, este paulatino descrédito de las instituciones no sólo es inmoral, no solo es ilegal, sino que desmoraliza, roba el ánimo al medio y largo plazo de la sociedad en su conjunto, y en una sociedad desanimada no puede emprenderse nada sólido. ${ }^{10}$

Afirmar que la ética es buen negocio desde la perspectiva económica puede parecer extraño y hasta disparatado cuando lo dominante es la corruptela y la negociación interesada de las reglas, los concursos públicos y otro tipo de transacciones que promueven los gobiernos. Sin embargo, aun desde la perspectiva de lo puramente económico, en términos de eficiencia y rentabilidad, el respeto a la ley y la observancia de valores como la transparencia y la pulcritud resultan convenientes. El rigor en el cumplimiento de la ley y de los contratos y, en general, el respeto al derecho, al eliminar la incertidumbre, disminuyen los riesgos y alientan la competencia legítima. Al contrario, la corrupción, como queda dicho, constituye un enorme costo oculto para los países, porque pervierte y devalúa la obra y el servicio públicos, aleja las inversiones serias de corporaciones controladas con códigos éticos fuertes y desalienta a los que no saben conducirse en el mundo precario y riesgoso de la coima y la mentira.

La experiencia está demostrando que no hay forma más eficiente de administrar los intereses del Estado que con pocos pero escrupulosos empleados que manejen lo ajeno con más rigor que lo propio. Pero hay que considerar que el manejo honorable de la cosa pública toca también y de manera fundamental el tema de la adecuada y transparente formulación de la leyes y de las políticas públicas. La

10. Cortina, Adela. Hasta un pueblo de demonios. Etica pública y sociedad, pág. 99. Edit. Taurus. 1998. 
transparencia personal de funcionarios y comités de gestión es ciertamente fundamental, pero no será eficaz si las reglas que ellos aplican no corresponden al afán de transparencia. Desde ese punto de vista, los sistemas legislativos y el ejercicio de potestades legales delegadas por parte de los gobiernos locales, deberían estar comprometidos con reglas básicas de integridad, admitiendo que este tema es especialmente arduo porque toca la índole misma de instituciones republicanas cuyo descrédito es grave.

De todas formas, parece importante y oportuno tratar asuntos de este tenor y proponer como regla de integridad esencial la de la revaluación del sentido económico de la ética y la de la función que ella tiene en el mercado en que incursionan los gobiernos, más aún si la obra pública tiene agentes privados que la ejecutan.

\section{La rendición de cuentas o la lealtad a la confianza ciudadana}

La rendición de cuentas es una institución clave del sistema democrático. En la doctrina, hay numerosas razones que la explican y soportan. Las más usuales son de carácter político: si el depositario y titular legítimo del poder es el pueblo, y si el pueblo encarga a sus mandatarios, por la vía del voto, el ejercicio limitado y reglado de ese poder ajeno, el gobernante está obligado de rendir cuentas de su uso. Por otra parte, la rendición de cuentas es una expresión del principio de sujeción a la ley y de vigencia del régimen de derecho, que somete a normas específicas la acción de las autoridades.

El principio jurídico de que en derecho público solamente se puede hacer lo que está expresamente mandado y previsto como potestad en una norma tiene su contrapartida en la rendición de cuentas, esto es, en la explicación de cómo se administran las reglas y cómo se ejercen las facultades. Este asunto tiene vinculación con el hecho de que el poder en los sistemas liberales es limitado y compartido. Además, juega el principio de que se trata de un poder responsable, en que el ejercicio de la autoridad acarrea deberes jurídicos específicos frente al mandante.

La rendición de cuentas tiene facetas políticas y constitucionales. Está en la base del sistema de delegación de poderes. Mucho se ha ocupado la literatura política de los enfoques normativos e institucionales. La literatura sobre las consideraciones éticas y cívicas del tema ha sido comparativamente escasa. Últimamente, se han ocupado con insistencia del tema pensadores de la talla de Victoria Camps, Adela Cortina, Fernando Savater y José Antonio Marina, quienes sostienen que la rendición de cuentas, como muchas otras instituciones del poder, tiene fundamentos éticos.

La dimensión ética de la rendición de cuentas es la contrapartida de la confianza que la comunidad deposita las au toridades. Su poder no puede estar anclado solamente en la ley y en el temor a la sanción. El poder no es eficiente si carece del soporte moral de la credibilidad de los ciudadanos. Cuando a la autoridad no se le cree, cuando desde el punto de vista de los ciudadanos ella no es fiable, los controles jurídicos pierden el soporte esencial y derivan hacia la ineficacia.

La democracia es el único sistema político que se fundamenta en actos éticos de los ciudadanos. Su legitimidad como poder se basa en el voto, y el voto es íntima 
confesión, elección personalísima de cada individuo, que vota porque cree en el candidato y en su programa. El encargo político tiene vinculación directa en el hecho de que el ciudadano se fía de un candidato y confía en sus propuestas, capacidad y honradez. De manera que la elección de la autoridad coloca a ésta en deuda frente a los electores. Y esa deuda se paga con la rendición de cuentas del poder ajeno, con la transparencia en la administración de la cosa pública, con la obligación de eficiencia, utilidad y oportunidad de la obra y del servicio público.

Si se admiten las tesis contractualistas en la explicación del origen del poder, si el Estado nace de un contrato social según las tesis liberales, cabría pensar, siguiendo la vieja tradición romana, que el contrato político que celebran los electores con sus mandatarios se basa en la buena fe, que deriva en la confianza y que coloca al gobernante en la obligación moral de honrarla. Probablemente una de las explicaciones del deterioro institucional y del descalabro de la democracia representativa esté en que los gobernantes actúan con mala fe, engañando a los electores y escamoteando la rendición de cuentas. Las leyes sobran cuando prospera la desconfianza. Los contratos -el contrato político- carecen de eficacia cuando están anclados en la buena fe, esto es, en los compromisos éticos de ambos contratantes.

Entre autoridad local y electores no solamente existe un vínculo jurídico-político que se canaliza y expresa por medio de las instituciones y las leyes. Además, se entabla entre ellos una relación ética, una lealtad, una obligación moral de coherencia entre la oferta electoral y la acción de gobierno. Este tema, vinculado con la rendición de cuentas, con el balance de eficacia democrática toca el asunto del populismo y las campañas entendidas como empresas electorales en las que se explota la credibilidad popular.

La confianza es uno de los pilares éticos en los que descansa la autoridad. Se puede defraudar a la ciudadanía y faltar a la lealtad que se le debe desde la autoridad, de varios modos: con la falta de coherencia entre la propuesta electoral con la cual se obtiene el voto y el verdadero plan de gobierno que se ejecuta; con la falta de oportunidad en la ejecución de la obra pública; con la defectuosa prestación de servicios; con la falta de transparencia en los procesos de contratación; con el dispendio de los recursos públicos ya sea inflando la burocracia, otorgándole prebendas o admitiendo prácticas corruptas; con la ejecución de obras innecesarias que responden a compromisos políticos o a prácticas caciquistas.

La rendición de cuentas es tema fundamental de la ética pública. Y esa rendición debería estar referida al ciertos principios o pautas que animan a la ética de la administración pública, que fueron sintetizados en el conocido Informe Nolan (Standards in Public Life), presentado en 1995 al Parlamento Británico y que Adela Cortina resume en: -desinterés, como compromiso de los que ocupan cargos públicos en tomar decisiones solamente bajo las consideraciones del interés público y con prescindencia absoluta del interés privado; - integridad, que alude al hecho de que los funcionarios no deben colocarse bajo ninguna obligación o compromiso financiero o de otra índole, que pueda influir en el desempeño de sus responsabilidades; -objetividad, al tomar decisiones y llevar a cabo los asuntos públicos, los nombramientos y los contratos, sin consideraciones que distorsionen la imparcialidad basada en los hechos; -responsabilidad, que se traduce en la rendición de cuentas y 
en la sujeción al escrutinio público de sus actos y omisiones; -transparencia, esto es, el imperativo moral de obrar en la forma más abierta, evitando la limitación de la información solamente a los casos en que tal limitación sea indispensable para el interés público; - honestidad, la única meta del funcionario es la protección efectiva y constante del interés público, lo que le obliga a prescindir de condicionamientos de otra índole y a poner de manifiesto los potenciales conflictos entre su interés privados y el colectivos; $y$, - liderazgo, tarea ética del funcionario es ejercer la autoridad en forma ejemplar, esto obrado de tal modo que su conducta arrastre y marque rutas frente al resto de la administración y a la colectividad. ${ }^{11}$

Estos son los referentes que la ciudadanía debería considerar en los procesos de rendición de cuentas, en los escrutinios constantes, expresos e implícitos que formule respecto del desempeño del gobierno. Hay que precisar y distinguir que la rendición de cuentas a que me refiero, más allá del deber jurídico que las reglas de la administración contienen, debería transformarse en un hábito de la autoridad frente a la comunidad, esto es, en un práctica constante, en una especie de cultura. Por su parte, la comunidad está llamada a ejercer esa práctica, encarnarla en la vida diaria. Solo así podrá la rendición de cuentas convertirse en un vínculo ético que soporte la confianza y la fidelidad en el ejercicio del gobierno local. Ese hábito, esa cultura de la sociedad, debería transformarse en una verdadera vigencia social, en el sentido que la vigencia tiene en la filosofía de Ortega y Gasset, es decir en una fuerza social vinculante que induzca consistentemente los comportamientos.

La vigencia social, según lo ha desarrollado ampliamente Julián Marías siguiendo a Ortega, en La Estructura Social, se conforma de referentes, valores o ideales de conducta que importan a los miembros de una sociedad, ya estén en el papel de ciudadanos o de autoridades, es decir que imponen lealtades entre ellas y que, eventualmente, cuando se las rompe, suscitan una sanción social, una descalificación o exclusión. Si a la autoridad local no le importa el prestigio que la credibilidad suscita, no será posible ni eficaz la rendición moral de cuentas. En ese sentido, si no existe una revalorización del concepto de prestigio, del nombre bien habido, de la confianza personal y de la fidelidad, la democracia seguirá la ruta de una formalidad política sin contenidos éticos eficaces, que la ley no puede suplir.

\section{La burocracia, sujeto y objeto de la ética pública}

Uno de los fenómenos más frecuentes en la administración de los intereses colectivos es el de la burocratización del poder, y más aún, la tendencia de los funcionarios de carrera y empleados, sindicalizados o protegidos por leyes de servicio civil y carrera administrativa, a constituir poderes paralelos dentro de las organizaciones, que controlan y desvían las decisiones, condicionan su ejecución, administran la información y quitan transparencia y oportunidad a los actos de gobierno.

Los gobiernos no existen sin administración profesional. Sin embargo, con frecuencia, la burocracia está sindicalizada y fuertemente protegida por los contratos colectivos y la ley. Pero no se han examinado a profundidad los condicionamientos burocráticos que recaen sobre el poder legítimo y la disolución de la representatividad y de los programas de gobierno en los memorandos, prácticas y secretos de la burocracia.

11. Cortina, Adela. Op. cit, pág. 161. 
Max Weber estudió con detenimiento el tema en su clásico libro ¿Qué es la burocracia? y sostuvo, con razón, que el poder político formal -el gobierno electo y sus cuadrosque se enfrenta con el funcionario adiestrado, incorporado a la dirección administrativa e investido de la jerarquía formal de un interlocutor válido, está en la situación del aficionado frente al experto. La burocracia guarda los secretos de la administración, custodia los archivos, protege la información. Con frecuencia, el secretismo asociado al profesionalismo del burócrata constituye una verdadera fuente de poder y origen de corrupción.

De otra parte, defectos profundos de los sistemas electorales son el populismo y el caciquismo, que derivan en el clásico clientelismo, que llena de personal innecesario las dependencias, distorsiona el gasto, confronta grupos humanos e induce al amiguismo en la contratación y a claras manifestaciones de corrupción en el uso de los recursos, en el manejo de concesiones, en el influjo político partidista en las decisiones, etc. La burocratización y el clientelismo son dos facetas importantes de los cuadros de corrupción en los gobiernos y son formas de disolución de la representatividad democrática.

No puede haber rendición de cuentas eficaz, ni estarán los gobiernos en capacidad de corresponder a la lealtad que le deben a la comunidad, ni transparentar procedimientos y decisiones, ni ser eficientes, ni invertir razonablemente los recursos, a menos que se regulen las atribuciones de la burocracia profesional y se racionalicen los regímenes laboral o administrativo que amparan a los funcionarios. Éstas son medidas jurídicas, pero, como en todo lo demás, los deberes y los límites legales serán insuficientes e ineficaces si a ellos no les acompañan reglas de integridad que deben cumplir los titulares de los gobiernos frente a la burocracia y desde la burocracia.

Los funcionarios deben ser sujetos de reglas de integridad y la sociedad civil debe habituarse a dirigir sus exigencias de comportamiento ético no solamente hacia los administradores visibles de los gobiernos, que generalmente proceden de elecciones o nominaciones públicas temporales. Deben dirigir sus ojos, sus exigencias y las reglas básicas de integridad a las burocracias de todos los niveles, porque más allá de la corrupción con ribetes políticos, hay la otra, la corrupción en la administración, la corrupción que anida en los mandos medios, las obscuridades que prosperan entre la abundancia de las reglas y la confusión de las potestades. Una fuente de corrupción es la abundancia de basura legal, constituida por miles de reglas secundarias expedidas por la burocracia, que entorpecen la administración y confunden a los ciudadanos. Otra fuente es el descrédito de la ley y el ejercicio de potestades discrecionales de todo orden, que colocan a la seguridad jurídica en entredicho y a los derechos subjetivos de los ciudadanos en constante incertidumbre.

La integridad indica que el clientelismo habitual de los partidos y otras corporaciones es conducta antiética y que una demanda de integridad es, sin duda, el compromiso ante la comunidad de no acrecentar innecesariamente la burocracia, de racionalizar el gasto, de transparentar los procedimientos de incorporación de personal y de respetar el profesionalismo de la administración. Tema arduo, sin duda, pero necesario este de dejar de considerar a los gobiernos como bolsas de empleo de los partidarios del líder de ocasión. 
En varias reglas de integridad debe comprometerse la burocracia de los gobiernos, a fin de profesionalizar de verdad los procedimientos, dar trato razonable a los usuarios, resistir a la tentación de la coima, esforzarse por incorporar una cultura de eficiencia y de excelencia en la prestación de los servicios públicos, evitar el dispendio de los recursos y colaborar con los gobiernos en los procesos de rendición de cuentas.

La burocratización de los gobiernos locales atenta contra la eficiencia, pues entorpece, retarda y diluye la prestación de servicios y la ejecución de obras, con costos innecesarios para la comunidad; atenta contra la transparencia, pues el secretismo, los códigos cifrados en comités y contratos, la manipulación de la ley y la abundante expedición de legislación secundaria encubre a la burocracia y obscurece la claridad de los procedimientos; atenta contra oportunidad del servicio y su mejora; atenta contra la idoneidad de la obra.

Por lo mismo, las reglas de la integridad deberían apuntar a rescatar el sentido de servicio de la administración, la claridad de las reglas, la objetividad de las decisiones, de modo de hacer posible la rendición de cuentas y elevar el aprecio general por la función pública, tan venida a menos en la mayoría de nuestros países, que para ello debe dar testimonios coherentes y comprometedores.

\section{La dimensión ética de los impuestos}

La economía para funcionar bien necesita instituciones eficaces, referentes éticos y prerrequisitos culturales. El mercado opera fundamentalmente con intereses y su punto central es el egoísmo racional, el afán de acumulación y la legitimidad de la ganancia. Pero no es menos cierto que el mercado debe contar con una red institucional y con un ambiente de hábitos de honradez, fidelidad al cliente, respeto a los contratos, espíritu de trabajo y eficiencia. Se requieren, por supuesto, convicciones que sirven de soportes culturales. Como bien escribió alguna vez Mariano Grondona, la prosperidad económica y el auge del mercado tienen como condiciones esenciales valores no económicos.

Los sistemas tributarios, al igual que el mercado, deben contar con valores no económicos, con referentes éticos que permitan la funcionalidad impositiva. De lo contrario la ley no opera y la defraudación campea en la sociedad.

Cuando se discute el incremento de los impuestos, lo que se expone como argumento únicamente es el déficit presupuestario, las necesidades crecientes, los gastos descubiertos. Las autoridades suponen, con frecuencia y descubriendo una notable superficialidad de análisis, que los impuestos son solamente cuestión de cifras y de leyes. Quienes están en los secretos de los indicadores del gasto presumen que la razón y la justificación se quedan únicamente en las cifras que presentan. Pero esa no es la verdad completa. El hecho cierto es que las cifras, al igual que las leyes, necesitan razones morales que las sustenten, porque la economía pública, sus presupuestos y demandas pueden ser técnicamente impecables, pero éticamente lesivos.

Los impuestos son la clave sin la cual no funciona una economía libre y un Estado y un gobierno soberanos. Pero los ciudadanos tienen que exigir a quienes ejercen 
el poder la legitimación social y moral del régimen tributario. La comunidad tiene derecho a saber -y los gobiernos están obligados a explicar- cuál es el destino de los impuestos y tarifas, cuál es relación con el financiamiento de la obra pública.

Los impuestos, como casi todo, encierran un problema ético vinculado, por una parte, con la transparencia en cuanto al destino de los impuestos y, además, con el comportamiento de los contribuyentes. Si para los ciudadanos es un deber legal y moral pagar los tributos, para los gobiernos es también obligación moral justificar su empleo, y ésta es una manifestación concreta de la rendición de cuentas.

Los gobiernos locales deberían tender hacia el autofinanciamiento, es la mejor forma de iniciar con paso firme el camino hacia la descentralización administrativa. Eso conlleva una apuesta a la integridad y a la transparencia. La cultura tributaria de la que tanto se habla no es sino un conjunto de hábitos y compromisos frente al gobierno, de lealtades, que deben nacer y desarrollarse en los contribuyentes a tal punto que inhiban, por convicción, las tentaciones evasoras. Eso, evidentemente está vinculado con la credibilidad del gobierno, con su prestigio.

En lo tributario, como en ningún otro asunto, es claro el vínculo ético que existe entre gobierno y ciudadanía. Hay en ese tema una especie de contraprestación de lealtades y confianzas, por eso, el mayor obstáculo para generar la cultura tributaria es la poca o ninguna transparencia de los gobiernos en cuanto al destino de los tributos, a la equidad y generalidad de las reglas, a la eficacia de la recaudación a los que más tienen, a la proporcionalidad de las tarifas. Los llamados principios de la tributación si bien inspiran a las leyes, constituyen también principios, valores y referentes que deben cuajar en la conducta de los administradores públicos y de los ciudadanos, antes que por medio de la ley, a través de los compromisos ciudadanos y los deberes morales de los gobiernos que deben coincidir en el mismo punto: en la mutua confianza, de los unos para entregar sus recursos a la administración y de los otros para honrar esa confianza empleando adecuadamente los fondos y dotando a la comunidad de servicios apropiados y oportunos y de obras públicas idóneas.

Probablemente la falta de valores y referentes éticos, la carencia de anclas culturales es lo que explica la debilidad tradicional de los regímenes de derecho. Allí está, quizá, el secreto de la ineficacia de las leyes y de esa sensación extendida de fraude colectivo que tiene la gente cuando de hablar de la política se trata.

Así, pues, el buen gobierno no depende exclusivamente de la Constitución ideal, ni de la perfección técnica de la las leyes. Depende, en gran medida, de la buena fe de los gobernantes, de los compromisos y lealtades de los gobernados, del valor de la palabra de la autoridad, de la eficacia de la ley. Depende de esa difusa, compleja e incómoda ética, cuya ausencia tdos lamentamos a la hora de hacer los balances después de los descalabros políticos y de las crisis financieras. 